\title{
Increased Uric Acid Promotes Decline of the Renal Function in Hypertensive Patients: A 10-year Observational Study
}

\author{
Yuko Ohta ${ }^{1,2}$, Takuya Tsuchihashi ${ }^{2}$, Kanako Kiyohara $^{2}$ and Hideyuki Oniki ${ }^{2}$
}

\begin{abstract}
Objective Uric acid (UA) has shown to be a causal risk factor for the development and progression of renal disease. The aim of this study was to investigate the relationship between changes in the level of UA and trends in the renal function among hypertensive patients during a 10-year observation period.

Methods The subjects included 104 hypertensive outpatients (60 women and 44 men, mean age 60 \pm 9 (SD) years at the first visit) who had undergone at least five instances of successful 24-hour home urine collection, with the first examination completed between 1998 and 2000 and the last examination completed between 2008 and 2010.

Results The estimated glomerular filtration rate (eGFR) significantly decreased over the 10.4-year observation period, with an average change in eGFR of $-0.66 / \mathrm{mL} / \mathrm{min} /$ year. The uric acid clearance at the last examination was significantly lower than that observed at the first visit, while there were no significant differences in the serum UA levels during this period. The change in serum UA exhibited a significant negative correlation with the change in eGFR $(\mathrm{r}=-0.34, \mathrm{p}<0.01)$. The patients whose UA level decreased more than $0.5 \mathrm{mg} /$ $\mathrm{dL}$ during the observation period demonstrated significantly smaller declines in eGFR compared to those whose UA level increased more than $0.5 \mathrm{mg} / \mathrm{dL}$. In the multivariate analysis, the change in serum UA and the average urinary salt excretion during the observation period were found to be significantly associated with the change in eGFR, independent of age, sex, BP changes or an increased number of antihypertensive drugs.

Conclusion Based on the findings observed over a 10-year observation period, increased UA is suggested to promote decline of the renal function in hypertensive patients. Controlling the level of UA as well as intensively restricting salt intake is required in order to preserve the renal function.
\end{abstract}

Key words: uric acid, 24-hour urine, renal function, hypertensive patients, uric acid clearance

(Intern Med 52: 1467-1472, 2013)

(DOI: 10.2169/internalmedicine.52.0141)

\section{Introduction}

The prevalence of hyperuricemia tends to increase as the number of patients with metabolic syndrome (Mets) increases. Although hyperuricemia is not included as a component of Mets, there is a possibility that it is mutually related to the development of Mets. An increased level of uric acid (UA) has shown to be associated with not only Mets, but also hypertension and the risk of cardiovascular diseases (1-6). We have previously reported that hypertensive patients with Mets are often complicated with hyperuricemia (7). It is well known that renal dysfunction causes hyperuricemia. However, evidence is accumulating that hyperuricemia itself causes arteriolosclerosis and/or interstitial damage of the kidneys without intrarenal UA crystal deposition, unlike the classic gouty kidney observed following UA crystal deposition (8-13). In the present study, therefore, we investigated the relationship between changes in the serum UA level and the renal function in hypertensive patients over a 10 -year observation period.

${ }^{1}$ Division of Hypertension and Nephrology, National Cerebral and Cardiovascular Center, Japan and ${ }^{2}$ Division of Hypertension, Clinical Research Institute, National Kyushu Medical Center, Japan

Received for publication January 15, 2013; Accepted for publication March 10, 2013

Correspondence to Dr. Yuko Ohta, ota.yuko.hp@ncvc.go.jp 
Table 1. Characteristics of the Subjects $(n=104)$

\begin{tabular}{lcc}
\hline & First visit & Last visit \\
\hline Male (\%) & 42 & - \\
Age (years) & $60 \pm 9$ & $70 \pm 9$ \\
Body weight $(\mathrm{kg})$ & $60.4 \pm 9.9$ & $58.9 \pm 10.8^{* *}$ \\
Body mass index $\left(\mathrm{kg} / \mathrm{m}^{2}\right)$ & $24.2 \pm 3.0$ & $23.6 \pm 3.3$ \\
Obesity $(\%$, body mass index $\geq 25)$ & 39.4 & $36.5^{* *}$ \\
Systolic blood pressure $(\mathrm{mmHg})$ & $144 \pm 12$ & $128 \pm 14^{* *}$ \\
Diastolic blood pressure $(\mathrm{mmHg})$ & $85 \pm 8$ & $68 \pm 11^{* *}$ \\
Number of antihypertensive drugs & $1.3 \pm 1.0$ & $2.3 \pm 1.1^{* *}$ \\
Urinary salt excretion $(\mathrm{g} /$ day) & $9.4 \pm 3.5$ & $7.9 \pm 3.1^{* *}$ \\
Urinary protein excretion $(\mathrm{g} / \mathrm{day})$ & $0.22 \pm 0.41$ & $0.10 \pm 0.23^{* *}$ \\
Blood urea nitrogen $(\mathrm{mg} / \mathrm{dL})$ & $15.7 \pm 3.7$ & $16.3 \pm 4.9$ \\
eGFR (ml/min/1.73m $\left.{ }^{2}\right)$ & $70.7 \pm 13.9$ & $63.7 \pm 15.7^{* *}$ \\
Serum uric acid $(\mathrm{mg} / \mathrm{dL})$ & $5.7 \pm 1.5$ & $5.5 \pm 1.1$ \\
Uric acid clearance $(\mathrm{mL} / \mathrm{min})$ & $7.5 \pm 2.7$ & $6.4 \pm 2.2^{* *}$ \\
\hline Values are means $\pm \mathrm{SD}, * * \mathrm{p}<0.01$ vs. First visit & \\
eGFR: estimated glomerular filtration rate &
\end{tabular}

\section{Materials and Methods}

Participants were recruited from among hypertensive outpatients who visited the National Kyushu Medical Center, Fukuoka, Japan. We assessed UA clearance using 24-hour home urine collection. The urine samples were collected at 24-hour intervals using a partition cup (proportional sampling method (14)) that collected $1 / 50$ of the urine over 24 hours. If the 24-hour creatinine excretion was within $\pm 30 \%$ of the estimated value, the urine collection was considered successful. The first examinations were performed between 1998 and 2000, and the last examinations were performed between 2008 and 2010. The subjects included 104 patients (60 women and 44 men, mean age: $70 \pm 9$ years) who underwent more than five successful 24-hour home urine collections during the follow-up period. The levels of urinary salt, UA and creatinine excretion were measured. BP was measured with a sphygmomanometer by the doctor while the patient was quietly seated. Hypertension was considered to be present if the patient had a systolic blood pressure (SBP) $\geq 140 \mathrm{mmHg}$ and/or a diastolic blood pressure (DBP) $\geq 90$ $\mathrm{mmHg}$ or was taking antihypertensive medications. The estimated glomerular filtration rate (eGFR) was calculated using the Modification of Diet in Renal Disease (MDRD) formula modified for Japanese individuals (for men, $0.741 \times 175 \times$ serum creatinine levels-1.154xage-0.203; for women, $0.741 \times$ $175 \times$ serum creatinine levels- $1.154 \times$ age- $0.203 \times 0.742(15))$. This study was performed in accordance with institutional guidelines and was approved by the ethical committee of our institution.

\section{Statistical analysis}

The values are presented as the mean \pm standard deviation (SD). The differences in the variables were compared using a one-way ANOVA. The chi-square test was also utilized when appropriate. $\mathrm{p}$ values of less than 0.05 were considered to be significant.

Results

Over an average period of 10.4 years, 104 subjects (60 women and 44 men, mean age: $60 \pm 9$ years at the first visit) underwent urine collection an average of 11.7 times. The characteristics of the subjects are shown in Table 1. BP and the level of urinary salt excretion decreased from $144 \pm 12$ / $85 \pm 8$ to $128 \pm 14 / 68 \pm 11 \mathrm{mmHg}$ and from $9.4 \pm 3.5$ to $7.8 \pm 3.1$ $\mathrm{g} /$ day over the 10.4-year observation period, respectively. In addition, the eGFR decreased significantly from $70.7 \pm 13.9$ to $63.7 \pm 15.7 \mathrm{~mL} / \mathrm{min} / 1.73 \mathrm{~m}^{2}$ and the average change in eGFR was $-0.66 \mathrm{~mL} / \mathrm{min} /$ year. The level of uric acid clearance at the last visit was significantly decreased compared to that observed at the first visit $(6.4 \pm 2.2$ vs. $7.5 \pm 2.7 \mathrm{~mL} /$ min, $\mathrm{p}<0.01)$; however, there were no significant differences in the serum UA levels over this period $(5.5 \pm 1.1$ vs. $5.7 \pm 1.5$ $\mathrm{mg} / \mathrm{dL}, \mathrm{ns})$. Table 2 shows the clinical characteristics of the subjects divided into three groups based on the change in the UA level over the observation period. The mean BP of each group decreased to the same extent over this period. However, the eGFR and the level of UA clearance at the last visit in the group whose UA level increased more than 0.5 $\mathrm{mg} / \mathrm{dL}$ and the group whose level remained between +0.5 and $-0.5 \mathrm{mg} / \mathrm{dL}$ were significantly decreased compared to those observed at the first visit (eGFR: $62.7 \pm 13.9$ vs. $69.4 \pm$ $12.4 \mathrm{~mL} / \mathrm{min} / 1.73 \mathrm{~m}^{2}, 63.1 \pm 13.4$ vs. $76.1 \pm 13.3 \mathrm{~mL} / \mathrm{min} / 1.73$ $\mathrm{m}^{2}$; UA clearance: $6.5 \pm 2.5$ vs. $7.3 \pm 2.5 \mathrm{~mL} / \mathrm{min}, 5.8 \pm 1.5$ vs. $8.9 \pm 2.6 \mathrm{~mL} / \mathrm{min}, \mathrm{p}<0.01$, respectively). In contrast, the subjects whose UA level decreased more than $0.5 \mathrm{mg} / \mathrm{dL}$ exhibited no significant changes in eGFR or UA clearance.

In the subanalysis of the 64 subjects who did not take diuretics or UA-lowering drugs during the observation period, BP and the level of urinary salt excretion similarly decreased over the 10.6-year observation period. In addition, the eGFR decreased significantly, and the average change in eGFR was $-0.50 \mathrm{~mL} / \mathrm{min} /$ year. The level of uric acid clearance at the last visit was significantly decreased; however, there were no significant differences in serum the UA levels over this period. Similar to the findings observed in all subjects, the eGFR and the level of UA clearance at the last visit in the group whose UA level increased more than 0.5 $\mathrm{mg} / \mathrm{dL}$ and the group whose level remained between +0.5 and $-0.5 \mathrm{mg} / \mathrm{dL}$ were significantly decreased compared to those observed at the first visit. On the other hand, the eGFR and the level of UA clearance at the last visit in the group whose UA level decreased more than $0.5 \mathrm{mg} / \mathrm{dL}$ improved compared to those observed at the first visit.

Fig. 1 shows the relationship between the change in the serum UA level and the change in eGFR. The change in the serum UA level exhibited a significant negative correlation with the change in eGFR among all subjects (A: $r=-0.34$ ), the subjects not taking diuretics or UA-lowering drugs (B: $\mathrm{r}=-0.45$ ) and the subjects in whom diuretics were newly administered during the observation period ( $\mathrm{C}: \mathrm{r}=-0.59)$.

Fig. 2 shows the trend in eGFR according to the change 
Table 2. Characteristics of the Subjects according to the Change in Serum Uric Acid $(n=104)$

\begin{tabular}{|c|c|c|c|c|c|c|}
\hline \multirow[t]{2}{*}{ Change in uric acid (mg/dL) } & \multicolumn{2}{|c|}{$\leq-0.5(n=31)$} & \multicolumn{2}{|c|}{$-0.5-+0.5(n=45)$} & \multicolumn{2}{|c|}{$+0.5(\mathrm{n}=28) \leq$} \\
\hline & First visit & Last visit & First visit & Last visit & First visit & Last visit \\
\hline Male $(\%)$ & 65 & - & 33 & - & 32 & - \\
\hline Age (years) & $60.3 \pm 8.9$ & $70.7 \pm 8.8$ & $59.6 \pm 8.3$ & $69.9 \pm 8.3$ & $58.6 \pm 9.4$ & $69.2 \pm 9.6$ \\
\hline Body weight (kg) & $62.5 \pm 10.2$ & $60.4 \pm 12.0 * *$ & $59.8 \pm 10.4$ & $58.4 \pm 11.1$ & $59.0 \pm 8.7$ & $58.0 \pm 9.1 * *$ \\
\hline Systolic blood pressure (mmHg) & $146 \pm 14$ & $130 \pm 13^{* *}$ & $143 \pm 11$ & $129 \pm 16^{* *}$ & $142 \pm 10$ & $126 \pm 10^{* *}$ \\
\hline Diastolic blood pressure (mmHg) & $87 \pm 7$ & $66 \pm 11 * *$ & $85 \pm 9$ & $68 \pm 12^{* *}$ & $85 \pm 8$ & $68 \pm 11 * *$ \\
\hline Number of antihypertensive drugs & $1.4 \pm 1.0$ & $2.3 \pm 1.1^{* *}$ & $1.2 \pm 1.1$ & $2.2 \pm 1.0 * *$ & $1.2 \pm 0.8$ & $2.4 \pm 1.2^{*}$ \\
\hline Urinary salt excretion (g/day) & $9.8 \pm 3.6$ & $8.4 \pm 3.4^{*}$ & $8.8 \pm 3.6$ & $7.7 \pm 3.0$ & $9.9 \pm 3.1$ & $7.8 \pm 3.2 *$ \\
\hline Urinary protein excretion (g/day) & $0.24 \pm 0.61$ & $0.14 \pm 0.29$ & $0.22 \pm 0.27$ & $0.09 \pm 0.23 * *$ & $0.19 \pm 0.34$ & $0.07 \pm 0.16$ \\
\hline Blood urea nitrogen $(\mathrm{mg} / \mathrm{dL})$ & $16.6 \pm 4.0$ & $16.5 \pm 5.1$ & $15.7 \pm 3.6$ & $16.8 \pm 5.6$ & $14.8 \pm 3.4$ & $15.5 \pm 3.3^{* *}$ \\
\hline $\mathrm{eGFR}\left(\mathrm{mL} / \mathrm{min} / 1.73 \mathrm{~m}^{2}\right)$ & $67.9 \pm 15.6$ & $65.8 \pm 19.8$ & $69.4 \pm 12.4$ & $62.7 \pm 13.9^{* *}$ & $76.1 \pm 13.3$ & $63.1 \pm 13.4^{* *}$ \\
\hline Serum uric acid (mg/dL) & $6.9 \pm 1.6$ & $5.4 \pm 1.2 * *$ & $5.5 \pm 1.2$ & $5.4 \pm 1.1$ & $4.7 \pm 1.0$ & $5.9 \pm 1.0 * *$ \\
\hline Uric acid clearance $(\mathrm{mL} / \mathrm{min})$ & $6.4 \pm 2.1$ & $6.7 \pm 2.4$ & $7.3 \pm 2.5$ & $6.5 \pm 2.5^{* *}$ & $8.9 \pm 2.6$ & $5.8 \pm 1.5^{* *}$ \\
\hline
\end{tabular}

Values are means $\pm \mathrm{SD},{ }^{* *} \mathrm{p}<0.01,{ }^{*} \mathrm{p}<0.05$ vs. First visit, eGFR: estimated glomerular filtration rate
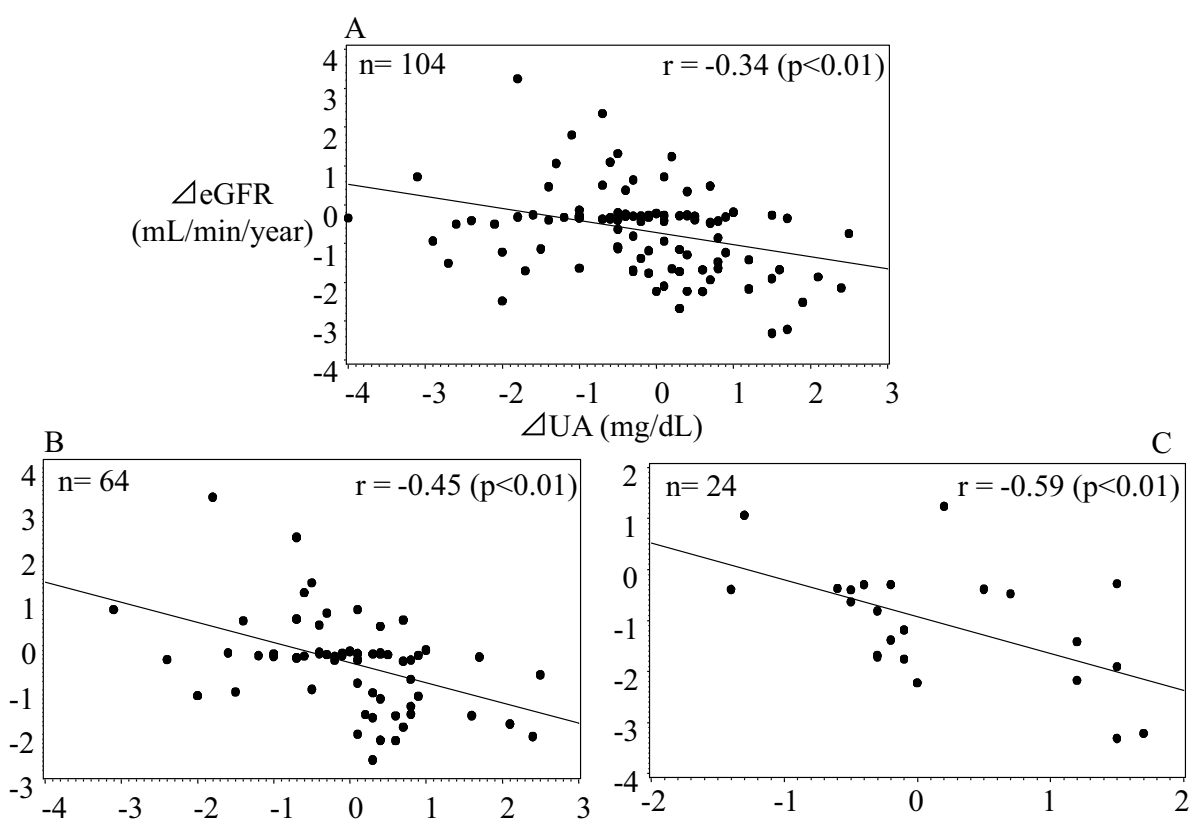

Figure 1. Correlation between the changes in eGFR and the changes in the serum uric acid levels among all subjects (A), subjects not taking diuretics or UA-lowering drugs (B) and subjects in whom diuretics were newly administered (C). eGFR: estimated glomerular filtration rate, UA: uric acid

in the serum UA level. The patients whose UA level decreased more than $0.5 \mathrm{mg} / \mathrm{dL}$ during the observation period exhibited significantly lower declines in eGFR than those whose UA level increased more than $0.5 \mathrm{mg} / \mathrm{dL}$, among all subjects $(-0.16 \pm 1.18$ vs. $-1.24 \pm 0.98 \mathrm{~mL} / \mathrm{min} /$ year, $\mathrm{p}<0.05$, Fig. 2A) as well as the subjects not taking diuretics or UAlowering drugs $(0.25 \pm 1.22$ vs. $-1.01 \pm 0.80 \mathrm{~mL} / \mathrm{min} /$ year, $\mathrm{p}<$ 0.05, Fig. 2B).

In the multivariate analysis, the change in the serum UA level and the average level of salt excretion during the observation period were found to be significantly associated with the change in eGFR among all subjects, independent of age, sex, BP changes or an increased number of antihypertensive drugs (Table 3A). Similarly, the change in the serum UA level and the eGFR at the first visit were found to be significantly associated with the change in eGFR among the subjects not taking diuretics or UA-lowering drugs (Ta- ble 3B).

\section{Discussion}

Over the 10-year observation period employed in the present study, changes in the serum UA level were found to be associated with a decline in the renal function among hypertensive patients. This decrease in the serum UA level protected against a decline in the eGFR, not only among all subjects, but also among subjects not taking diuretics or UA-lowering drugs.

Hyperuricemia is often observed in patients with lifestylerelated diseases, such as hypertension or Mets, and elevated UA levels are reported to be a risk factor for cardiovascular disease $(1,3-5,7)$. Mets has been found to be associated with abnormalities in the release of adipocytokines from fatty cells and visceral fat accumulation, both of which con- 
eGFR

$\left(\mathrm{mL} / \mathrm{min} / 1.73 \mathrm{~m}^{2}\right)$

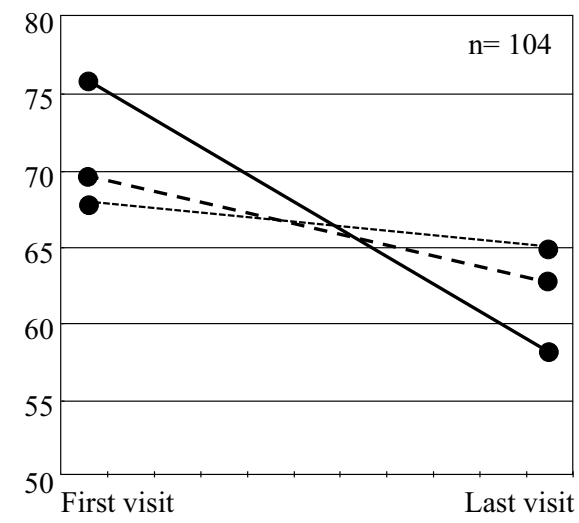

eGFR

$\left(\mathrm{mL} / \mathrm{min} / 1.73 \mathrm{~m}^{2}\right)$

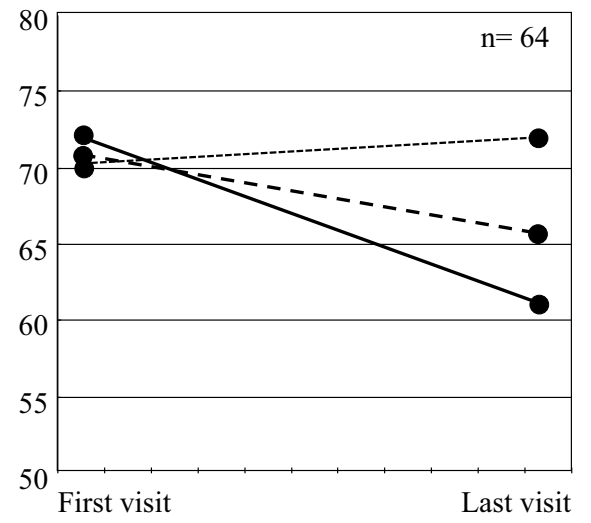

$-\triangle \mathrm{UA} \geq 0.5 \mathrm{mg} / \mathrm{dL}$

$---0.5<\triangle \mathrm{UA}<0.5 \mathrm{mg} / \mathrm{dL}$

…… $\Delta \mathrm{UA} \leq-0.5 \mathrm{mg} / \mathrm{dL}$

Figure 2. Trend in eGFR according to the changes in the serum uric acid levels among all subjects (A) and subjects not taking diuretics or UA-lowering drugs (B). eGFR: estimated glomerular filtration rate, UA: uric acid

Table 3A. Clinical Factors Contributing to the Change in eGFR in All Subjects (n=104) -Multivariate Analysis-

\begin{tabular}{lcc}
\hline & Partial R & $\mathrm{p}$ \\
\hline The change in serum uric acid $(\mathrm{mg} / \mathrm{dL})$ & -0.34 & $<0.01$ \\
Average urinary salt excretion $(\mathrm{g} /$ day) & -0.32 & $<0.01$ \\
Body weight at the first visit $(\mathrm{kg})$ & -0.16 & 0.06 \\
eGFR at the first visit $\left(\mathrm{mL} / \mathrm{min} / 1.73 \mathrm{~m}^{2}\right)$ & -0.16 & 0.08 \\
\hline Independent variables: age, sex, first BP, last BP, the change in body weight \\
during observation period, the change in BP during observation period, \\
increased number of antihypertensive drugs \\
eGFR: estimated glomerular filtration rate, BP: blood pressure
\end{tabular}

tribute to insulin resistance (16). Insulin has been shown to increase $\mathrm{Na}^{+}$reabsorption via its actions on sodiumdependent monocarboxylate transporter 1 in the proximal renal tubules. The organic anion concentration in renal tubular cells increases in association with increases in $\mathrm{Na}^{+}$reabsorption, which activate UA reabsorption through UA transporter 1 , leading to hyperuricemia with decreased UA excretion. The observation that body weight reduction increases UA clearance and decreases the serum UA level supports the contribution of insulin resistance to hyperuricemia $(17,18)$. Therefore, advice regarding lifestyle modifications, including restricting salt intake and controlling body weight, are important for the management of hyperuricemic patients with Mets.

Hyperuricemia has also shown to be closely related to the development and progression of chronic kidney disease (CKD) (5, 8-12, 19-26). Gouty kidney with UA crystal deposition is known to be a complication of hyperuricemia. Concerning the mechanisms underlying the effects of hyperuricemia on the progression of CKD and the roles of insulin resistance, chronic interstitial nephritis with UA crystal deposition and arteriolonephrosclerosis due to hypertension, lipid and glucose abnormalities have been suggested. Re-
Table 3B. Clinical Factors Contributing to the Change in eGFR in Subjects without Taking Diuretics or UA Lowering Drugs ( $n=64)$-Multivariate Analysis-

\begin{tabular}{lcc}
\hline & Partial R & $\mathrm{p}$ \\
\hline The change in serum uric acid $(\mathrm{mg} / \mathrm{dL})$ & -0.45 & $<0.01$ \\
eGFR at the first visit $\left(\mathrm{mL} / \mathrm{min} / 1.73 \mathrm{~m}^{2}\right)$ & -0.44 & $<0.01$ \\
Body weight at the first visit $(\mathrm{kg})$ & -0.19 & 0.06 \\
\hline Independent variables: age, sex, first BP, last BP, the change in body weight \\
during observation period, the change in BP & during observation period, \\
increased number of antihypertensive drugs & & \\
eGFR: estimated glomerular filtration rate, UA: uric acid, BP: blood pressure
\end{tabular}

cently, the presence of renal damage without intrarenal UA crystal deposition has also been reported (5, 8-12). Uric acid is taken into vascular smooth muscle cells through the organic anion transporter, and the production of plateletderived growth factor and monocyte chemoattractant protein-1 is promoted through the actions of mitogen activated protein kinase. These compounds activate nuclear factor- $\mathrm{\kappa B}$, produce cyclooxygenase-2 (COX-2) and synthesize local thromboxane $\mathrm{A}_{2}$. As a result, renal vascular lesions are induced by inflammation of the vascular endothelium and proliferation of vascular smooth muscle cells. Furthermore, UA in vascular smooth muscle cells produces reactive oxygen species and activates the renin-angiotensin system (RAS) to produce local angiotensin II. Taken together, UA is suggested to play a key role in the development of renal microvascular disease, inflammation and the activation of RAS and COX-2, all of which aggravate renal disease and hypertension and induce endothelial dysfunction and cardiovascular disease $(5,8-10,12,13,19,26,27)$.

Lowering the serum UA level has been shown to prevent not only glomerulonephrosclerosis and tubulointerstitial fibrosis, but also cardiovascular events $(19,26,28,29)$, sug- 
gesting that providing appropriate treatment of hyperuricemia in the management of CKD is important. Many hypertensive patients who require treatment with a multiple number of antihypertensive drugs are complicated with hyperuricemia, obesity, lipid abnormalities or impaired glucose tolerance. Therefore, providing not only strict BP control, but also aggressive UA management is necessary in hypertensive patients complicated with multiple cardiovascular risk factors. In addition, hyperuricemia is divided into three types, an overproduction type, a decreased excretion type and a mixed type, based on the underlying mechanism (30). Therefore, the therapeutic strategy should be determined after identifying the mechanism of hyperuricemia. Most hypertensive patients have been reported to have the decreased UA excretion type of hyperuricemia (31). Therefore, it is appropriate to administer benzbromarone, a uricosuric agent, rather than allopurinol, a xanthine oxidase inhibitor, in hypertensive patients with the decreased UA excretion type of hyperuricemia.

One limitation associated with our study is that we did not investigate the prescription of specific ARBs that may potentially lower the serum UA levels. Although there were no significant differences in the use of $\mathrm{ARBs}$, both at the first and last visits, between the patients with increased and those with decreased UA levels, possible differences in the prescription of UA-lowering ARBs may have influenced the changes in the UA levels observed during the observation period.

In conclusion, an elevated level of UA was suggested to promote decline in the renal function in hypertensive patients over a 10-year observation period. In addition to BP control, uric acid control and intensive salt restriction are required to preserve the renal function in hypertensive patients.

The authors state that they have no Conflict of Interest (COI).

\section{References}

1. Krishnan E, Kwoh K, Schumacher R, Kuller L. Hyperuricemia and incidence of hypertension among men without metabolic syndrome. Hypertension 49: 298-303, 2007.

2. Bos MJ, Koudstaal PJ, Hofman A, Witteman JCM, Breteler MMB. Uric acid is a risk factor for myocardial infarction and stroke. Rotterdam study. Stroke 37: 1503-1507, 2006.

3. Ishizaka N, Ishizaka Y, Toda E, Nagai R, Yamakado M. Association between serum uric acid, metabolic sundrome, and carotid atherosclerosis in Japanese individuals. Arterioscler Thromb Vasc Biol 25: 1038-1044, 2005.

4. Hjortnaes J, Algra A, Olijhoek J, et al. Serum uric acid levels and risk for vascular diseases in patients with metabolic syndrome. J Rheumatol 34: 1882-1887, 2007.

5. Johnson RJ, Kang DH, Feig D, et al. Is there a pathogenetic role for uric acid in hypertension and cardiovascular and renal disease? Hypertension 41: 1183-1190, 2003.

6. Kawai T, Ohishi M, Onishi M, et al. Serum uric acid is an independent risk factor for cardiovascular disease and mortality in hypertensive patients. Hypertens Res 35: 1087-1092, 2012.

7. Ohta Y, Tsuchihashi T, Onaka U, Hasegawa E. Clustering of car- diovascular risk factors and blood pressure control status in hypertensive patients. Intern Med 49: 1483-1487, 2010.

8. Kang DH, Nakagawa T. Uric acid and chronic renal disease: possible implication of hyperuricemia on progression of renal disease. Semin Nephrol 25: 43-49, 2005.

9. Yu MA, Sánchez-Lozada LG, Johnson RJ, Kang DH. Oxidative stress with an activation of the rennin-angiotensin system in human vascular endothelial cells as a novel mechanism of uric acidinduced endothelial dysfunction. J Hypertens 28: 1234-1242, 2010 .

10. Mazzali M, Kanellis J, Han L, et al. Hyperuricemia induces a primary renal arteriopathy in rats by a blood pressure-independent mechanism. Am J Physiol Renal Physiol 282: F991-F997, 2002.

11. Sánchez-Lozada LG, Tapia E, Avila-Casado C, et al. Mild hyperuricemia induces glomerular hypertension in normal rats. Am $\mathrm{J}$ Physiol Renal Physiol 283: F1105-F1110, 2002.

12. Kanbay M, Solak Y, Dogan E, Lanaspa MA, Covic A. Uric acid in hypertension and renal disease: the chicken or the egg? Blood Purif 30: 288-295, 2010.

13. Mazzali M, Hughes J, Kim YG, et al. Elevated uric acid increases blood pressure in the rat by a novel crystal-independent mechanism. Hypertension 38: 1101-1106, 2001.

14. Tochikubo O, Uneda S, Kaneko Y. Simple portable device for sampling a whole day's urine and its application to hypertensive outpatients. Hypertension 5: 270-274, 1983.

15. Matsuo S, Imai E, Horio $\mathrm{M}$, et al; Collaborators developing the Japanese equation for estimated GFR. Revised equations for estimated GFR from serum creatinine in Japan. Am J Kidney Dis 53: 982-992, 2009.

16. Fujimoto WY, Abbate SL, Kahn SE, Hokanson JE, Brunzell JD. The visceral adiposity syndrome in Japanese-American men. Obes Res 2: 364-371, 1994.

17. Park HS, Sim SJ, Park JY. Effect of weight reduction on metabolic syndrome in Korean obese patients. J Korean Med Sci 19: 202-208, 2004.

18. Yamashita S, Matsuzawa Y, Tokunaga K, Fujioka S, Tarui S. Studies on the impaired metabolism of uric acid in obese subjects: marked reduction of renal urate excretion and its improvement by a low-calorie diet. Int J Obes 10: 255-264, 1986.

19. Talaat KM, El-Sheikh AR. The effect of mild hyperuricemia on urinary transforming growth factor beta and the progression of chronic kidney disease. Am J Nephrol 27: 435-440, 2007.

20. Sonoda H, Takase H, Dohi Y, Kimura G. Uric acid levels predict future development of chronic kidney disease. Am J Nephrol 33: 352-357, 2011

21. Miao Y, Ottenbros SA, Laverman GD, et al. Effect of a reduction in uric acid on renal outcomes during losartan treatment: a post hoc analysis of the reduction of endpoints in non-insulindependent diabetes mellitus with the Angiotensin II Antagonist Losartan Trial. Hypertension 58: 2-7, 2011.

22. Weiner DE, Tighiouaart H, Elsayed EF, Griffith JL, Salem DN, Levey AS. Uric acid and incident kidney disease in the community. J Am Soc Nephrol 19: 1204-1211, 2008.

23. Obermayr RP, Temml C, Gutjahr G, Knechtelsdoefer M, Oberbauer R, Klauser-Braun R. Elevated uric acid increases the risk for kidney disease. J Am Soc Nephrol 19: 2407-2413, 2008.

24. Iseki K, Ikemiya Y, Inoue T, Iseki C, Kinjo K, Takishita S. Significance of hyperuricemia as a risk factor for developing ESRD in a screened cohort. Am J Kidney Dis 44: 642-650, 2004.

25. Ito $\mathrm{S}$, Naritomi H, Ogihara $\mathrm{T}$, et al. Impact of serum uric acid on renal function and cardiovascular events in hypertensive patients treated with losartan. Hypertens Res 35: 867-873, 2012.

26. Kang DH, Nakawawa T, Feng L, et al. A role for uric acid in the progression of renal disease. J Am Soc Nephrol 13: 2888-2897, 2002.

27. Kang DH, Park SK, Lee IK, Johnson RJ. Uric acid-induced C- 
reactive protein expression: implication on cell proliferation and nitric oxide production of human vascular cells. J Am Soc Nephrol 16: 3553-3562, 2005.

28. Kanbay M, Ozkara A, Selcoki Y, et al. Effect of treatment of hyperuricemia with allopurinol on blood pressure, creatinine clearance, and proteinuria in patients with normal renal functions. Int Urol Nephrol 39: 1227-1233, 2007.

29. Goicoechaea M, Vinuesa SG, Verdalles U, et al. Effect of allopurinol in chronic kidney disease progression and cardiovascular risk.
Clin J Am Soc Nephrol 5: 1388-1393, 2010.

30. Committee for the preparation of guidelines for the management of hyperuricemia and gout, Japanese Society of Gout and Nucleic acid Metabolism: guidelines for the management of hyperuricemia and gout. Tokyo, Japanese Society of Gout and Nucleic acid Metabolism, Tokyo, 2010.

31. Yamamoto Y, Matsubara K, Igawa G, et al. Status of uric acid management in hypertensive subjects. Hypertens Res 30: 549-554, 2007.

(C) 2013 The Japanese Society of Internal Medicine http://www.naika.or.jp/imonline/index.html 